\title{
Evaluation of thunderstorm indices from ECMWF analyses, lightning data and severe storm reports
}

\author{
Rudolf Kaltenböck ${ }^{\mathrm{a}, \mathrm{b}, *}$, Gerhard Diendorfer ${ }^{\mathrm{c}}$, Nikolai Dotzek ${ }^{\mathrm{d}, \mathrm{e}}$ \\ a Austrocontrol-Aviation Weather Service, Schnirchgasse 11, A-1030 Vienna, Austria \\ b Universität Innsbruck, Institut für Meteorologie und Geophysik, A-6020 Innsbruck, Austria \\ c Austrian Electrotechnical Association (OVE), A-1190 Vienna, Austria \\ d Deutsches Zentrum für Luft- und Raumfahrt (DLR)-Institut für Physik der Atmosphäre, Oberpfaffenhofen, 82234 Wessling, Germany \\ e European Severe Storms Laboratory (ESSL), Münchner Str. 20, 82234 Wessling, Germany
}

\section{A R T I C L E I N F O}

\section{Article history:}

Received 19 December 2007

Received in revised form 7 November 2008

Accepted 14 November 2008

\section{Keywords:}

Severe local storms

Sounding parameters

Tornadoes

Thunderstorm indices

Forecasting deep moist convection

\begin{abstract}
A B S T R A C T
This study describes the environmental atmospheric characteristics in the vicinity of different types of severe convective storms in Europe during the warm seasons in 2006 and 2007. 3406 severe weather events from the European Severe Weather Database ESWD were investigated to get information about different types of severe local storms, such as significant or weak tornadoes, large hail, damaging winds, and heavy precipitation. These data were combined with EUCLID (European Cooperation for Lightning Detection) lightning data to distinguish and classify thunderstorm activity on a European scale into seven categories: none, weak and 5 types of severe thunderstorms. Sounding parameters in close proximity to reported events were derived from daily high-resolution T799 ECMWF (European Centre for Medium-range Weather Forecasts) analyses.

We found from the sounding-derived parameters in Europe: 1) Instability indices and CAPE have considerable skill to predict the occurrence of thunderstorms and the probability of severe events. 2) Low level moisture can be used as a predictor to distinguish between significant tornadoes or non-severe convection. 3) Most of the events associated with wind gusts during strong synoptic flow situations reveal the downward transport of momentum as a very important factor. 4) While deep-layer shear discriminates well between severe and non-severe events, the storm-relative helicity in the $0-1 \mathrm{~km}$ and especially in the $0-3 \mathrm{~km}$ layer adjacent to the ground has more skill in distinguishing between environments favouring significant tornadoes and wind gusts versus other severe events.

Additionally, composite parameters that combine measurements of buoyancy, vertical shear and low level moisture have been tested to discriminate between severe events.
\end{abstract}

(c) 2008 Elsevier B.V. All rights reserved.

\section{Introduction}

Operational meteorologists routinely prepare forecasts of thunderstorm initiation, their potential for severity, duration and possible storm motion. The ingredients for deep moist convection are instability, moisture and an initiating lifting

\footnotetext{
* Corresponding author. Austrocontrol, Air Navigation Service-MET, Schnirchgasse 11, A-1030 Vienna, Austria. Tel.: +43 51703 4014; fax: +43 517034006.

E-mail address: rudolf.kaltenboeck@austrocontrol.at (R. Kaltenböck).
}

process (e.g. Johns and Doswell, 1992; Doswell et al., 1996). For severe and organised long-living local storm development, a sufficient amount of convective potential available energy (CAPE) and vertical wind shear is needed.

Parameters derived from radiosonde and numerical weather prediction model data are often used to bring all the thermodynamic and kinematic vertical information in the troposphere together for preparing an overview of the possible thunderstorm spectrum and a synopsis over larger regions. Parameters that predict the likelihood of thunderstorms are e.g. Lifted Index (Galway, 1956), original and modified Showalter 


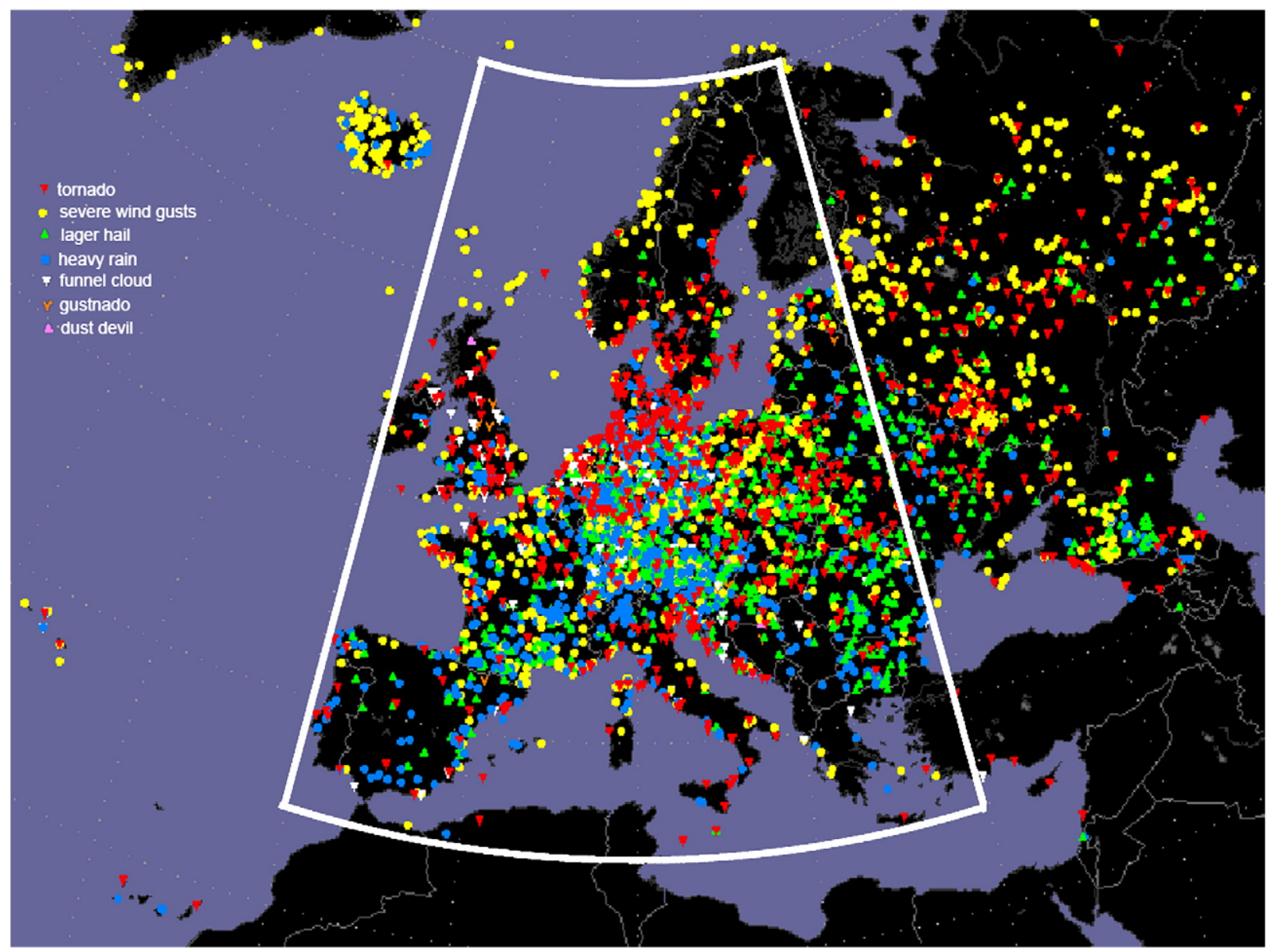

Fig. 1. Spatial distribution of all 4993 severe weather events from the ESWD database between 1.2.2006 and 21.8.2007. Area of interest from $-10^{\circ} \mathrm{W}$ to $30^{\circ} \mathrm{E}$ and $35^{\circ} \mathrm{N}$ to $70^{\circ} \mathrm{N}$ is marked by a white line and includes 3406 reported events for our selected time interval.

Index for Alpine regions (Showalter, 1953; Steinacker, 1977), and mid-troposphere lapse rate. Proximity sounding studies which have focused on the spectrum of severe storms are e.g. Bidner (1970, Severe weather threat SWEAT), Brooks et al. (1994, tornadic and non tornadic mesocyclones), Huntrieser et al. (1997, SWISS Index for Switzerland), Davis and Johns (1993, Energy-Helicity index), Tudurí and Ramis (1997) or Gayà et al. (2001, for the western Mediterranean), Rasmussen and Blanchard (1998, Shear-CAPE and storm-relative helicity), Thompson et al. (2003, Significant Tornado Parameter), Rasmussen (2003, low level shear), Groenemeijer and van Delden (2007, for the Nederlands), Kaltenböck (2000a, 2005, for Austria) and Brooks (2007, comparison between Europe and the United States (US)). For a different definition of severe storms see e.g. Doswell (1994a,b), Mills and Colquhoun (1998), or Brooks (2007).

Romero et al. (2007) created a synthetic climatology of severe convection which was tested on 85 significant tornadoes in the past. Brooks (2007) and Brooks et al. (2007) compared proximity soundings for severe events from Europe and the US from reanalysis data from the period 19581999. It seems that, given any severe weather that occurs, peak values of European probabilities for certain types of severe weather are higher than in the US, but the conditions for severity are met more seldom. European environments are similar to those seen in the cool season of south-eastern US (Brooks, 2007) and California (e.g. Monteverdi et al., 2003) with low lifting condensation level (LCL) heights and moderate CAPE.

In Europe, synoptic forcing and local influences (e.g. orography) are predominant for thunderstorm initiation. Case studies of severe weather events in Europe (e.g. Schmid et al., 2000; Kaltenböck, 2000a,b, 2004, 2005; Kaltenböck et al., 2004; Dotzek et al., 2001, 2007; Hannesen et al., 1998, 2000) identified the importance of local, mesoscale effects (e.g. orographic influences, convergence zones). High-resolution model data, especially for the wind and moisture fields, contain these mesoscale effects.

Since 2006 the European severe weather database ESWD (http://eswd.eu) has been operational, which for the first time provides severe weather reports for all of Europe. This well-documented dataset (ESSL, 2006; Dotzek et al., 2009-this issue) combined with high resolution ECMWF analyses gives the authors the opportunity to create this proximity sounding study for different severe events on a European scale. This is the first work of this 


\section{EJEUCLID}

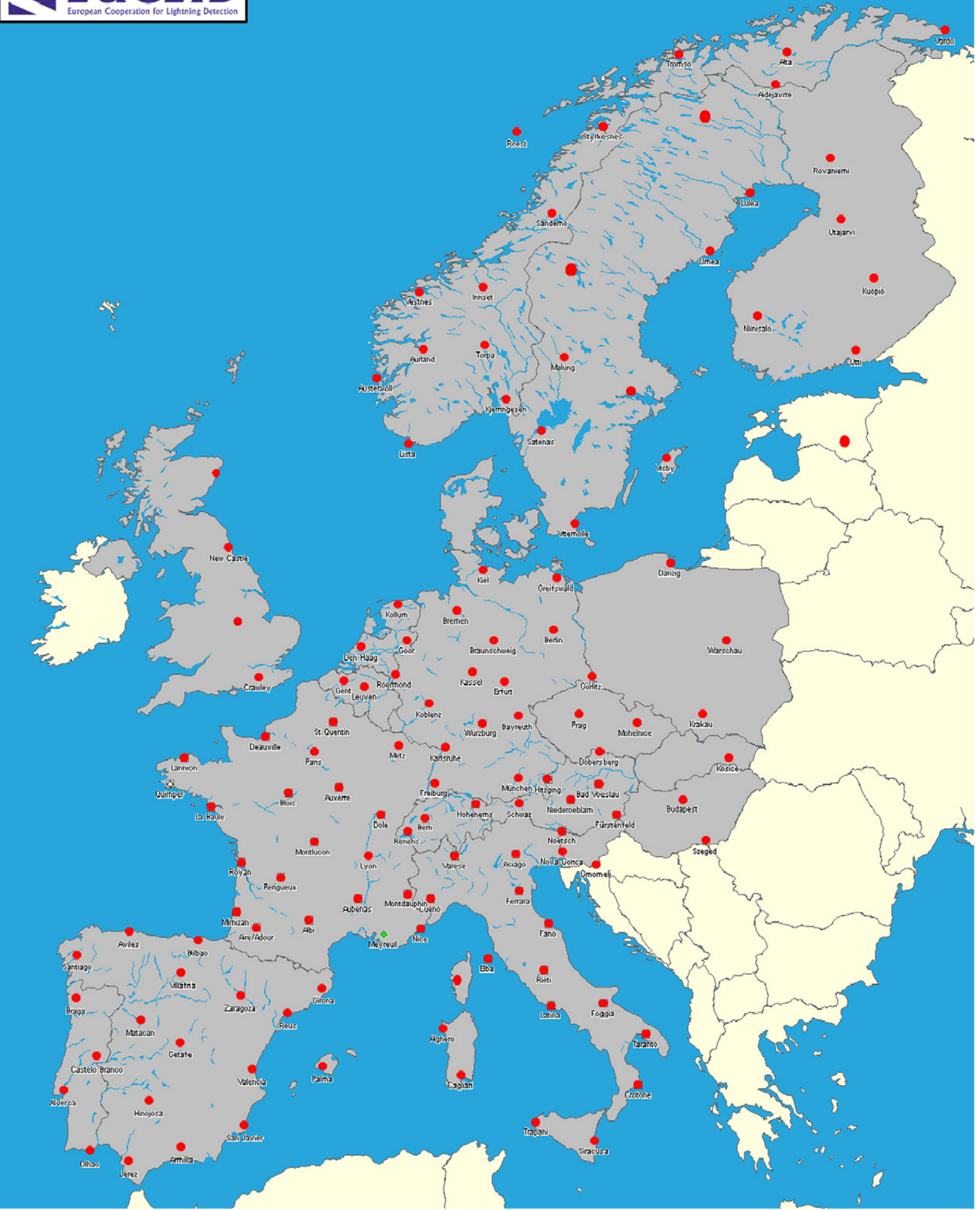

Fig. 2. European Cloud to Ground Lightning network EUCLID with marked location of detection sensors. 
kind for Europe, based on a vast amount of data. In this study, severe storm reports from Europe are used to prepare a climatology of proximity sounding parameters derived from numerical model data. Null cases, at the same location where severe weather events occurred, were selected by applying lightning data. Subsequently appropriate predictors result for the likelihood of thunderstorm occurrence and to discriminate between different types of severe thunderstorms.
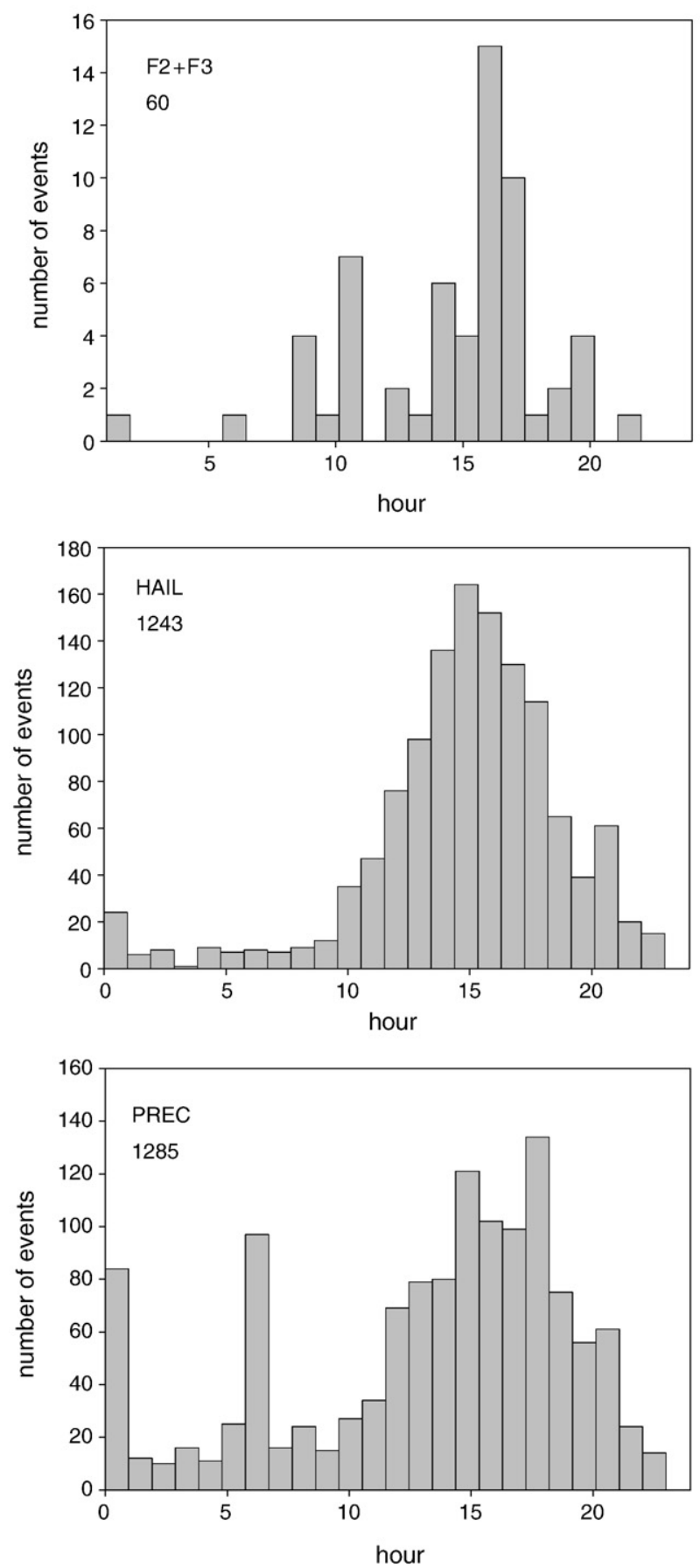

In the following, Section 2 describes the data used, Section 3 presents the results, and Section 4 gives our conclusions.

\section{Data and methodology}

\subsection{ESWD (European Severe Weather Database)}

The ESWD database (www.essl.org/ESWD/) is hosted by the European Severe Storms Laboratory (ESSL) and started
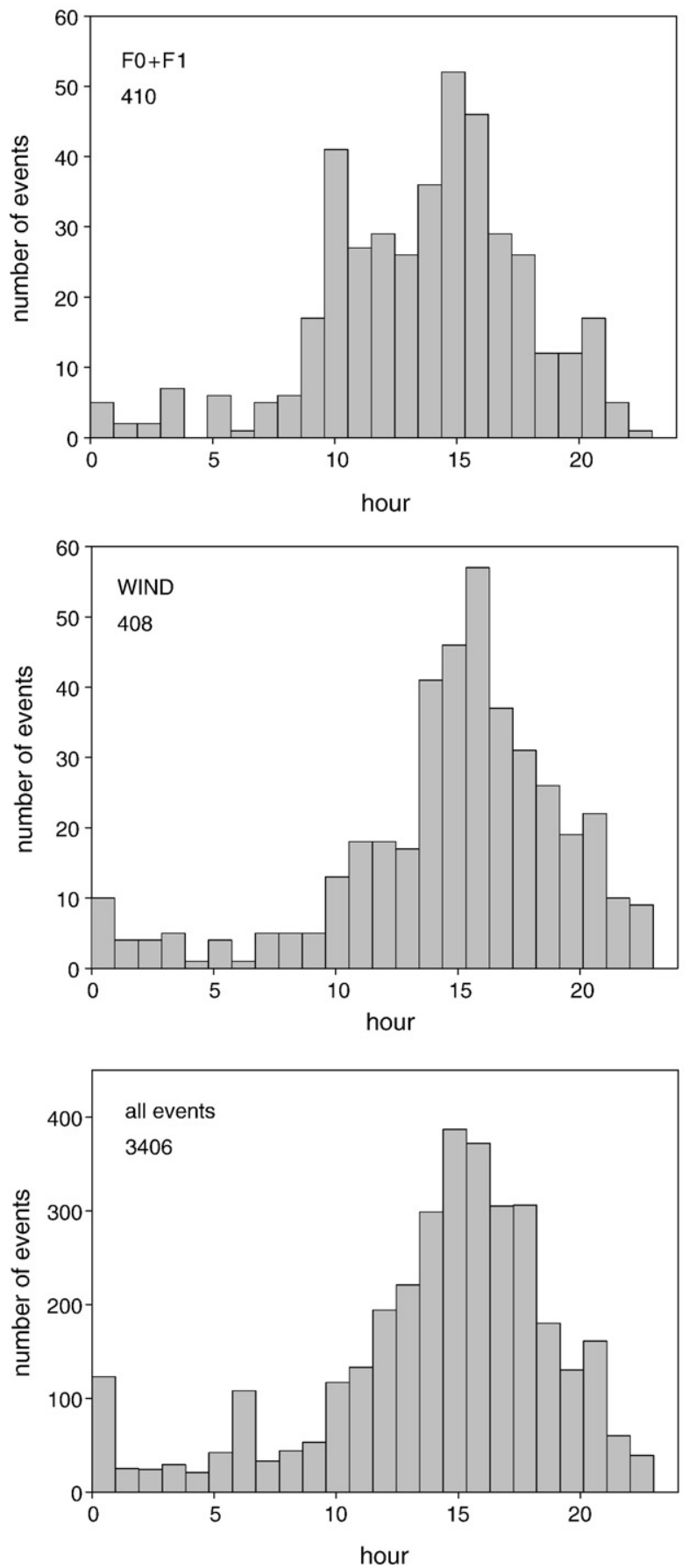

Fig. 3. Time distribution (in UTC) and number of selected ESWD events. For definition of the categories see text or Table 1. 
operational service in 2006. It collects and provides detailed and quality-controlled data on severe convective storm events over Europe (cf. Dotzek et al., 2009-this issue) using an interoperable data format (ESSL, 2006), and a web-based interface, where both ESSL staff, collaborating national meteorological and hydrological services, as well as the public can contribute and retrieve reports. About 3500 reports are collected each year.

Public severe weather reports are only retained in the ESWD if they pass a check for plausibility and multiplicity and then receive the lowest quality-control level QCO. If a public report can be further verified and enhanced by independent sources, its quality-control level will be raised accordingly to QC1 or even QC2. Our present analysis includes all public reports, as quality-control experience with the public input has shown that even the QCO reports are rarely affected by mistakes (like indicating local time instead of UTC in a report) and thus add valuable information needed to complete the picture of a given severe weather day.

Fig. 1 shows the spatial distribution of 4993 severe storm events over entire Europe between 1 February 2006 and 21. August 2007. No data beyond 21 August 2007 are used since this study was presented on the European Conference on Severe Storms in Trieste in the beginning of September 2007, but analysis of a larger time period is planned for the future.

The different types of convective severe weather events used in this work are:

1) Tornadoes over land and their intensity

2) Hail with diameter of $2 \mathrm{~cm}$ or more, or smaller hailstones that form a layer of $2 \mathrm{~cm}$ thickness or more on the earth surface

3) Damaging wind gusts with measured wind speeds of $25 \mathrm{~m} / \mathrm{s}$ or higher, or wind damage inflicted by winds that were likely stronger than $25 \mathrm{~m} / \mathrm{s}$

4) Heavy precipitation causing damage is observed, or in case of no damage, precipitation amounts exceptional for the region in question have been recorded, or one of the following limits of precipitation accumulation is exceeded: $30 \mathrm{~mm}$ in $1 \mathrm{~h}, 60 \mathrm{~mm}$ in $6 \mathrm{~h}, 90 \mathrm{~mm}$ in $12 \mathrm{~h}$, $150 \mathrm{~mm}$ in $24 \mathrm{~h}$, respectively.

ESWD dust devil and funnel cloud reports are not considered here, neither are the few reported gustnadoes attributed to wind events. No higher tornado intensity than F3 was reported within the study period. So, when speaking of significant tornadoes (F2 or higher) in the following, this includes only F2 and F3 events.

For this study, ESWD data are selected during the warm season to focus on convective weather events and minimize the number of synoptically forced large-scale events like fronts or low pressure systems. The selected periods were: 1 April to 30 September 2006 and 1 April to 21 August 2007. Geographical effects with large scale influence, like the autumn precipitation maximum in the Mediterranean (e.g. Romero et al., 1998) are not included in this timeframe.

The area was selected from $-10^{\circ} \mathrm{W}$ to $30^{\circ} \mathrm{E}, 35^{\circ} \mathrm{N}$ to $70^{\circ}$ $\mathrm{N}$. This is smaller than available ESWD. The constraint is lightning network detection efficiency (see Section 2.3). To focus on events on land, all ESWD reports over water were excluded.
The total number of events was 3406 at 1309 locations on 267 days, with respect to a spatial resolution of $0.25^{\circ}$, which is the resolution of ECMWF analyses. Each event was assigned using every severe report in the database (e.g. a tornado event accompanied by significant hail was assigned to two events).

\subsection{ECMWF (European Centre for Medium-range Weather Forecasts)}

High resolution ECMWF analyses from the T799 model were used, which are available for 2006 and 2007. The operational dataset from ECMWF covers our selected area with spatial grid resolution of $0.25^{\circ}$ (about $25 \mathrm{~km}$ ), 91 vertical levels and temporal intervals of $6 \mathrm{~h}$ for analyses. This aspect allows us to create close pseudo-soundings to investigate environmental conditions associated with severe thunderstorms. Since most of the severe events occurred during daytime, analysis data from 0600, 1200 (1300CET) and 1800 UTC were used to represent the daily convective situation.

\subsection{EUCLID (European Cooperation for Lightning Detection)}

EUCLID is a collaborative effort of national lightning detecting networks with the aim of identifying and detecting lightning all over Europe from Portugal to Warsaw and from Sicily to the North of Norway. The network provides lightning data with homogenous quality in terms of detection efficiency and location accuracy for most parts of Europe. The positions of lightning detection sensors are given in Fig. 2. This figure shows a low coverage of sensors in the south-eastern part of Europe, where the detection efficiency decreases with the distance to the lightning event especially for lower peak currents. The complete network consists of 75 sensors in 13 countries (EUCLID, 2007). Additional cooperation agreements are made for the Iberian Peninsula, contributing to the detection of lightning.

Lightning data for all 1309 used ESWD report locations were available for the time period from 1 April 2006 to 30 September 2006 and 1 April 2007 to 17 August 2007. For this study, EUCLID provided cloud-to-ground (CG) lightning data, including polarity with $1 \mathrm{~h}$ time resolution.

A day was classified as thundery, when lightning struck within a radius of $50 \mathrm{~km}$ from the location of reported severe events from the ESWD database, anytime between 0900 and 2200 UTC. This time frame reflects the diurnal cycle (see Fig. 3) and highlights the convective origin of severe events, which are driven by solar radiation (cf. Dotzek, 2001; Dotzek and Friedrich, 2009-this issue). About $86 \%$ of all reported events occurred between 0900 and 2200 UTC, more than $90 \%$ of all reports contained tornadoes and hail.

\subsection{Classification and proximity criteria}

In case of a strict proximity criterion, the sample set will represent the storm environment rather well, but in low numbers. Otherwise, a larger sample size from relaxation of the criterion may not represent the storm environment well.

To solve the critical problem of appropriate null cases in any proximity studies (e.g. Brooks 2007) a daytime period (0900-2200 UTC) for lightning data is used considering most 
Table 1

Definitions and numbers of proximity soundings for different severe local storm events over Europe during 2006 and 2007 (April-September).

\begin{tabular}{lll}
\hline Number & Event-category & Definition/ESWD or EUCLID \\
\hline 60 & F2 +F3 & Significant tornado (F2 or higher) \\
410 & F0 +F1 & Weak tornado (F0/F1) \\
1243 & HAIL & Large hail/layer greater/equal $2 \mathrm{~cm}$ \\
408 & WIND & Damaging wind gusts greater/equal $25 \mathrm{~m} / \mathrm{s}$ \\
1285 & PREC & Heavy precipitation \\
99664 & TS & 2 or more CG strikes and no ESWD-report \\
317641 & NO & 0-1 CG strikes \\
\hline
\end{tabular}

days with thunderstorm activity (without local severe events) or not, comparable to a time period of $11 \mathrm{~h}$ in the analysis by Huntrieser et al. (1997). This is in contrast to $6 \mathrm{~h}$ and $185 \mathrm{~km}$ threshold for proximity criteria of Brooks and Craven (2002) and Craven et al. (2002). In this study, lightning strikes within $50 \mathrm{~km}$ of the selected location are used to consider thunderstorm activity-or not-on a local scale. To find appropriate null cases, a lightning threshold of 1 CG flash is consistent with operational forecast experience of possible false detections (for the used $13 \mathrm{~h}$ time period) and with the criteria established by Reap (1986) and used e.g. by Craven et al. (2002). Other studies have used from zero CG strike (e.g. for Europe Huntrieser et al., 1997) to 9 or fewer CG strikes (Rasmussen and Blanchard, 1998) for the nothunder category.

Lightning data from the EUCLID network and convective severe weather reports from the ESWD database are utilized to divide the data set into 7 categories (Table 1 ):

$\mathrm{NO}=$ non-thunderstorm class (fewer than 2 CG flashes), $\mathrm{TS}=$ thunderstorm class (more than 1 CG flash), PREC = heavy precipitation reports, WIND = damaging wind gusts reported, $\mathrm{HAIL}=$ large hail (diameter of $2 \mathrm{~cm}$ of more or hail layer thickness of $2 \mathrm{~cm}$ or more), F0-F1 = weak tornado reports, F2$\mathrm{F} 3=$ significant tornadoes
These data were compared to ECMWF analysis data. 0600 UTC were used for events which occurred between 0000 and 0800 UTC, 1200 UTC for 0900-1500 UTC and 1800 UTC for 1600-2300 UTC.

\section{Results and discussions}

\subsection{Two-year warm season climatology}

\subsubsection{Spatial distribution}

The spatial distribution for reported local severe events over Europe for a two warm seasons is given in Fig. 1. Tornadoes are reported from far south, the Canary Islands to far north, Scandinavia. The number of severe weather reports may be correlated with population density (cf. Dotzek, 2001, 2003). There is a gradient from reported hail events in the south to wind events in the north. Observations of tornadoes are wide spread over entire Europe. (cf. Dotzek, 2003).

\subsubsection{Daily and monthly distribution}

The diurnal distributions of classified ESWD events are shown in Fig. 3. The diurnal cycle is well pronounced in the histograms. The peak values in the late afternoon between 1500 and 1600 UTC reflect the influence of solar radiation to force deep moist convection. For both weak and significant tornado groups, the histograms show a secondary maximum at 1000 UTC. Reasons for that could be the wide longitudinal extension of the test area, covering several time zones or vague observation time by reports, or even earlier development of convection during enhanced low level moisture conditions (see Fig. 7). Precipitation events seem to be highly correlated to synoptic observation time intervals of 0000 , 0600, 1200, 1800 UTC, when precipitation observations in SYNOP reports exceed the ESWD-thresholds and consequently may find their way into the ESWD database as additional reports.

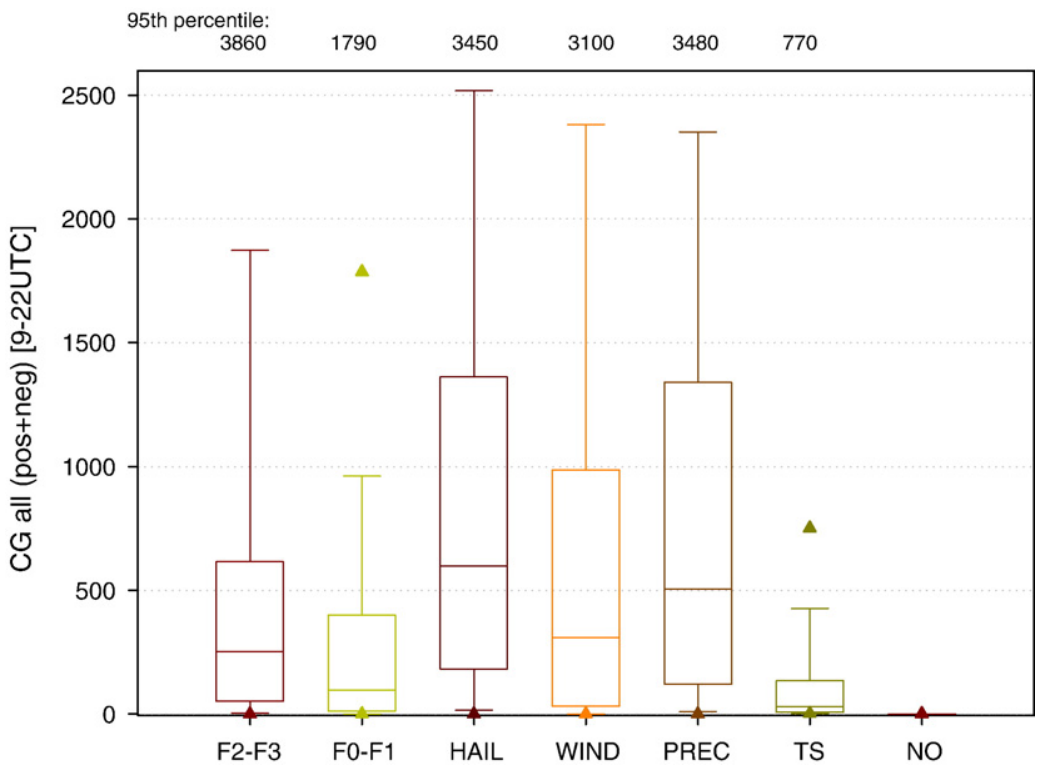

Fig. 4. Box and whisker plot of the total amount of CG-lighting between 0900 and 2200 UTC for each case of severe weather category. The boundary of the box closest to zero indicates the 25th percentile, a line within the box marks the median, and the boundary of the box farthest from zero indicates the 75th percentile. Whiskers ("error bars") above and below the box indicate the 90th and 10th percentiles. In addition the $5 \%$ and $95 \%$ percentile is graphed as points. 


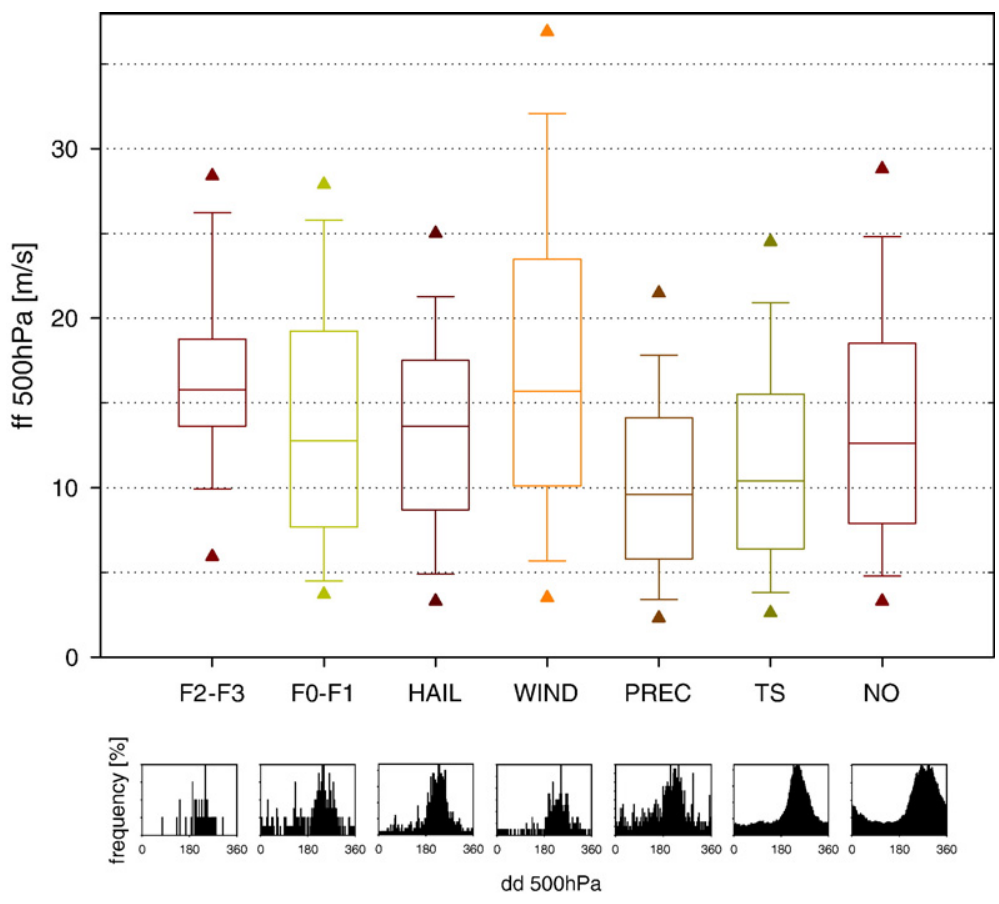

Fig. 5. As in Fig. 4, but for the wind speed at $500 \mathrm{hPa}$ (above) and frequency distribution of wind direction at $500 \mathrm{hPa}$ (below).

The annual cycle of thunderstorm activity (not shown) is biased due to the absence of data from September 2007. These distributions show low frequency for severe events in April and September. The maximum of significant tornado activity is in August, for weak tornado occurrence in July and August (cf. Holzer, 2001), for large hail in June, for severe wind gusts in Mai to July, for heavy rain in July and for ordinary thunderstorms a weak peak occurs in April.

\subsubsection{Lightning activity}

A summary of CG lightning strikes of positive and negative polarity between 0900 and 2200 UTC within $50 \mathrm{~km}$ of the reported ESWD events according to the 7 convection modes is given in a box-and-whiskers plot in Fig. 4. For occurrence of severe weather, generally more CG flashes are likely (e.g. Hohl and Schiesser, 2001, Williams, 2001). Days with ordinary thunderstorms show the lowest values of lightning amount (Fig. 4). The highest value of the 95th percentile (3860 lightning) is analysed by a small number of significant tornado days.

Overall, the highest lighting activity (50th, 75th and 90th percentile) happened on days with significant hail. Very few hail events occurred without related lightning strikes, due to either possible erroneous severe event reports or lack of lightning detection (most non-detected cases are in the south-east of the study area, where the coverage of sensors and the detection efficiency is low, Fig. 2).

About $10 \%$ of reported wind and F0-F1 events were not accompanied by flashes, indicating the predominance of synoptic-scale systems, the contribution of non-supercell tornadoes or again, reporting and detection errors. Days accompanied by weak tornadoes had less lightning intensity than F2 and F3 tornado days (median: 97 to 253). Reasons for that could be low-topped supercells at higher latitudes (e.g. Teittinen et al., 2006) or supercells accompanied by a weak instability environment, low CAPE values (Fig. 8) and subsequent weak updrafts. The lightning activity for F2/F3 category days extended from a few strikes to more than thousands of flashes. The high lightning rates for the precipitation category indicate that warm-season storms accompanied by heavy rain are mainly of convective origin.

Since lightning data during daytime were used to identify null-cases, Results differ systematically from studies using analyses of lightning activity for shorter time periods (e.g. Soula et al., 2004).

\subsubsection{Synoptic flow}

The synoptic flow over Europe was dominated by southwesterly winds (Fig. 5) at higher levels for all classes of thunderstorms. For these thundery days the advection of unstable warm air can be expected (cf. Bissolli et al., 2007). Analyses of helicity (not shown) reveal the warm air advection during daytime at lower levels. For the "no-thunderstorm" class, the maximum of $500 \mathrm{hPa}$ wind direction was shifted to westerly winds.

Wind velocities at $500 \mathrm{hPa}$, the representative midtropospheric level, were highest for reported severe wind events (Fig. 5). This illustrates the relevance of downward transport of momentum for such events, which is sometimes considered to be more important than the evaporation process from precipitation (e.g., Geerts, 2001; Dotzek and Friedrich, 2009-this issue; Dotzek et al., 2009-this issue). In organised local storms, a pronounced rear-flank downdraft (RFD) or dry rear inflow develops more easily with higher wind velocities (e.g. Kaltenböck 2004) and subsequent wind storm damages may be triggered. 


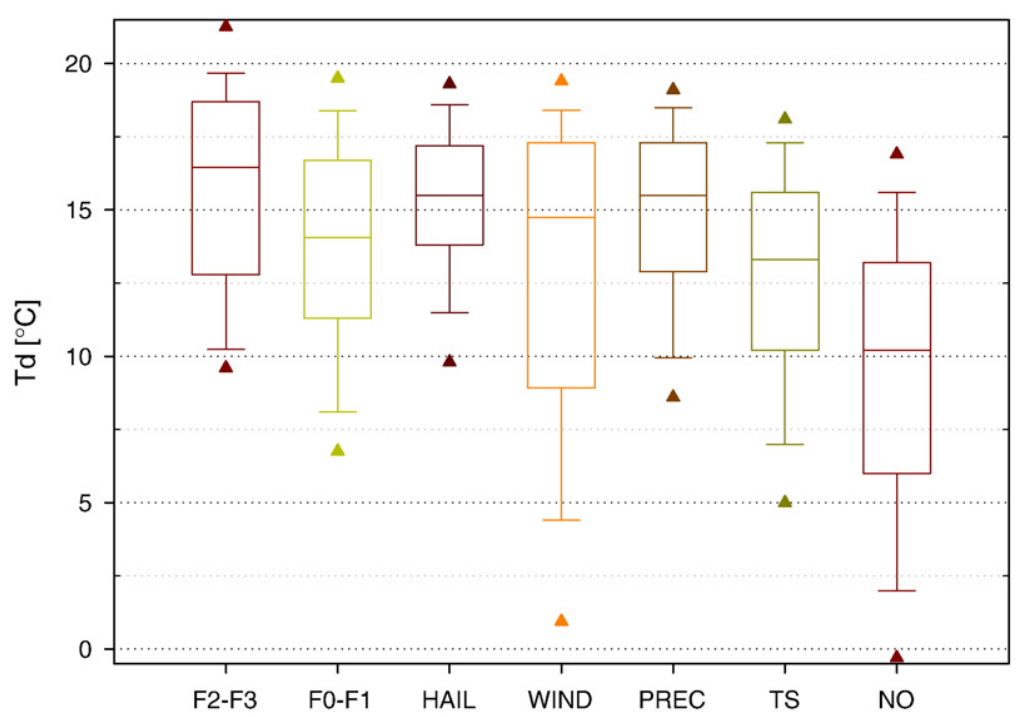

Fig. 6. As in Fig. 4, but for dew point in degrees Celsius of lowest model level.

Significantly higher wind values at $500 \mathrm{hPa}$ occurred for F2/F3 tornado events compared to F0/F1 tornadoes and hail events. These findings indicate the role of increasing wind speed with height due to vertical shear (Fig. 10) and the presence of a developed RFD. Markowski (2007) mentioned the likely role of RFDs for tornadogenesis accompanied by small temperature deficits of cold outflow at the ground. The results of this study (Fig. 5) can also be compared to stormrelative winds at $500 \mathrm{hPa}$, which were stronger for tornadic supercells (Thompson, 1998). The severe precipitation cases show lowest synoptic flow speed, resulting in slow-moving thunderstorms ("slow movers") accompanied by sufficient CAPE (cf. Fig. 8). In addition, there are also no significant differences between PREC and TS categories for deep and lowlevel shear (Figs. 10, 11, 12).

\subsubsection{Low level moisture}

To characterise the low level moisture, the dew point at the lowest model level and the lifted condensation level (LCL) is used. The first parameter is easy to measure and shows clearly the skill to distinguish between non-thundery and thundery events. When dew points exceed 10 to $13{ }^{\circ} \mathrm{C}$, thunderstorms are more likely (neglecting mesoscale influences and synoptic situation (Fig. 6).

$75 \%$ of TS cases have dew points below $15.5{ }^{\circ} \mathrm{C}$ while highest low-level moisture was found for significant tornadoes. The median of dew point is approximately at $16,5^{\circ} \mathrm{C}$, the 95th percentile close to $21.5^{\circ} \mathrm{C}$. Values were lower for $\mathrm{F} 0 / \mathrm{F} 1$ category (median $=14{ }^{\circ} \mathrm{C}, 95 \%$ quantile $=18.4{ }^{\circ} \mathrm{C}$ ). Therefore the height of LCL (Fig. 7) can be used to distinguish between significant and non-significant tornadoes. Lower LCL heights

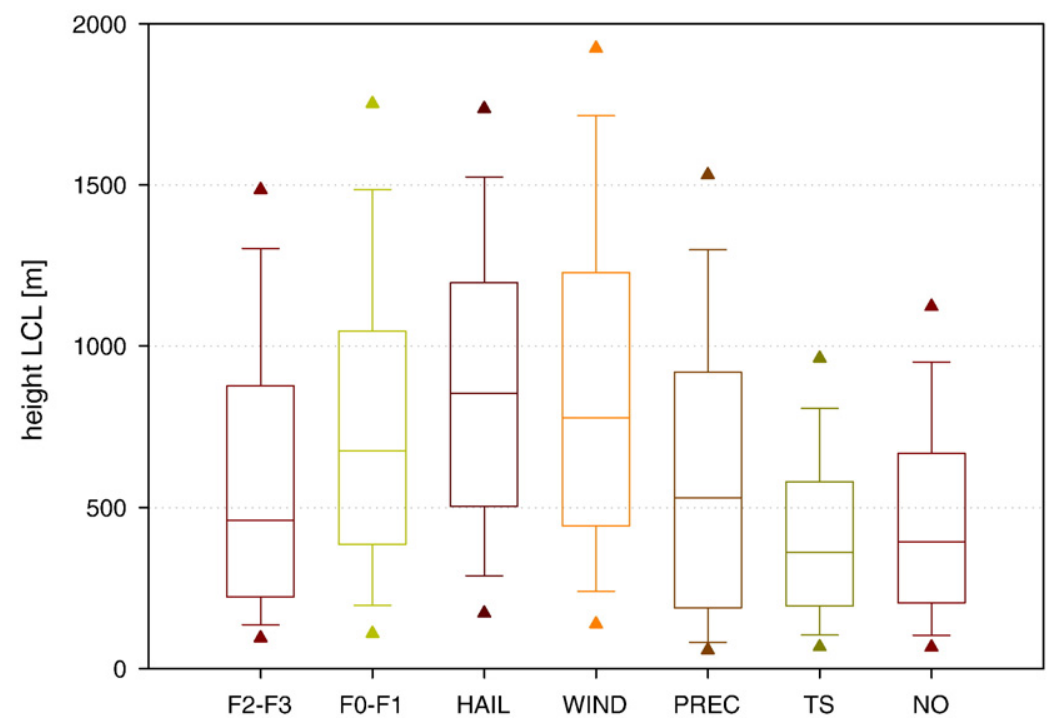

Fig. 7. As in Fig. 4, but for the lifting condensation level height above model surface. 


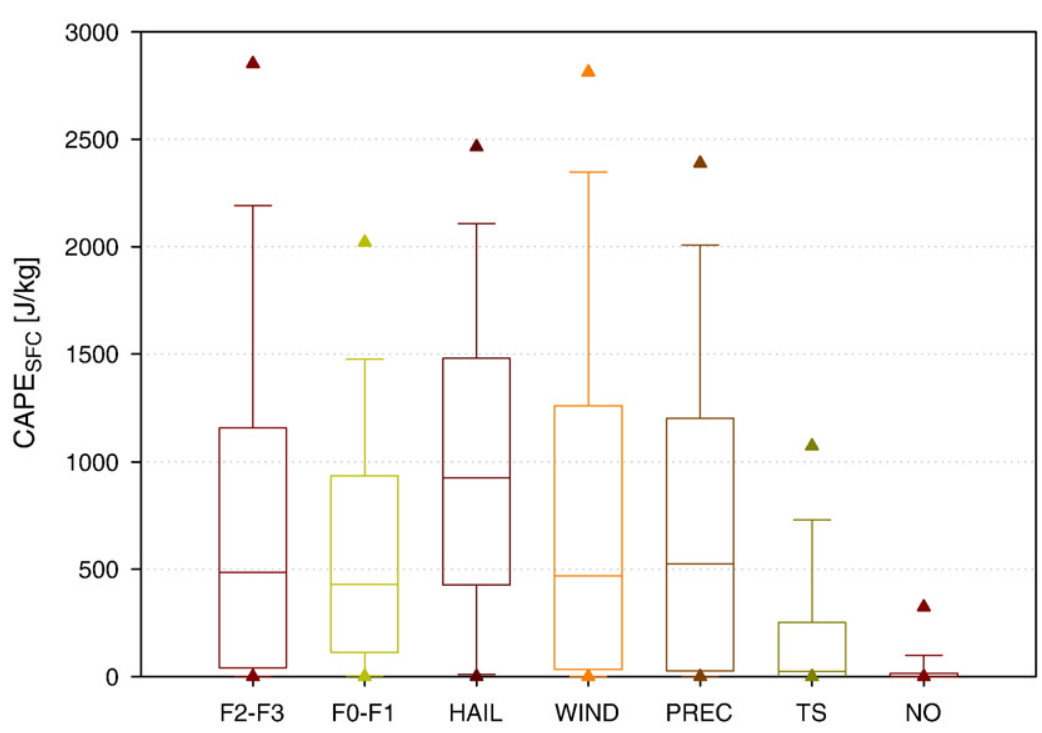

Fig. 8. As in Fig. 4, but for CAPE.

(mean value of $460 \mathrm{~m}$ above model surface) are given for F2F3 tornado class and differ from other classes except TS and PREC category.

The wind events accompanied by largest LCL heights indicate the influence of entrainment and evaporation effects within this data collective, but as mentioned before, it seems that high values of synoptic flow are as necessary to produce severe wind gusts.

\subsection{Thermodynamic parameters-instability}

To analyse the thermodynamic instability, the following parameters are derived: a) convective available potential energy (CAPE) related to the lowest model level, b) Showalter index (SHW), calculated from temperature and dew point at
850 hPa (Showalter, 1953; Huntrieser et al., 1997) and c) the temperature difference between 850 and $500 \mathrm{hPa}$. The 10th and 90th percentile for the latter (not shown) are 23 and $31{ }^{\circ} \mathrm{C}$ respectively for severe local storms.

\subsubsection{CAPE}

There is a wide range of surface parcel-based CAPE values for thunderstorm activity in Europe from few hundreds of $\mathrm{J} /$ $\mathrm{kg}$ to values of few thousands, shown in Fig. 8 (cf. Brooks et al., 2007; Brooks and Dotzek, 2008). CAPE can be used to distinguish between thunderstorms and non-thunderstorm classes (75\% of TS cases had values below $250 \mathrm{~J} / \mathrm{kg}$ ) and to discriminate between ordinary thunderstorms and severe events, especially HAIL, because there was no overlap in the middle $50 \%$. More than $75 \%$ of hail-bearing soundings exceed

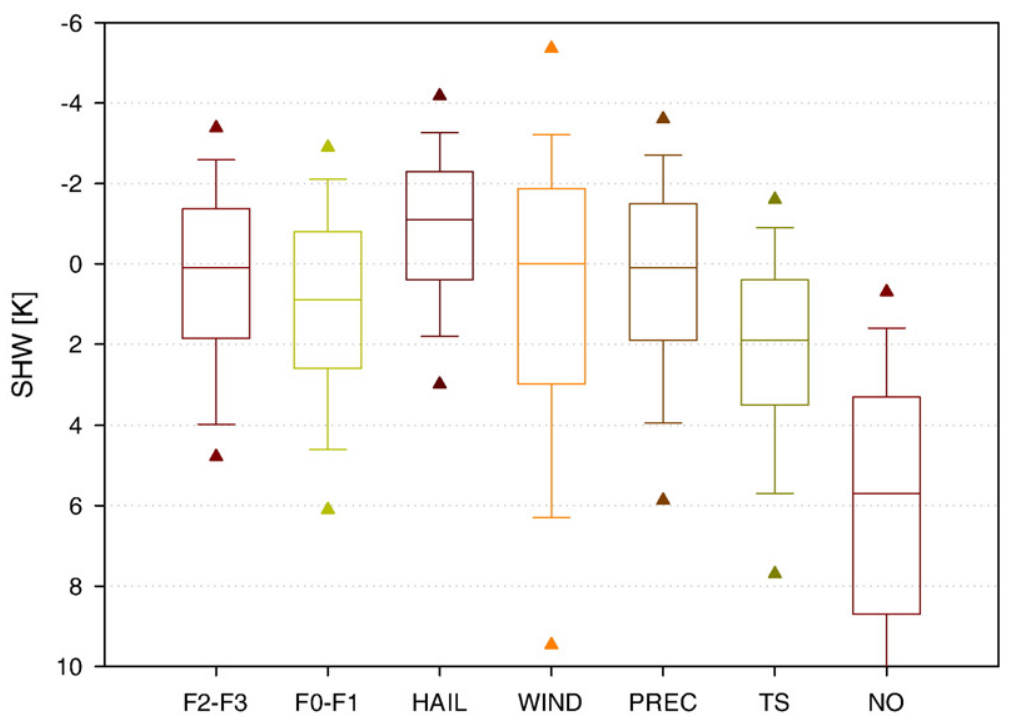

Fig. 9. As in Fig. 4 but for Showalter index. 


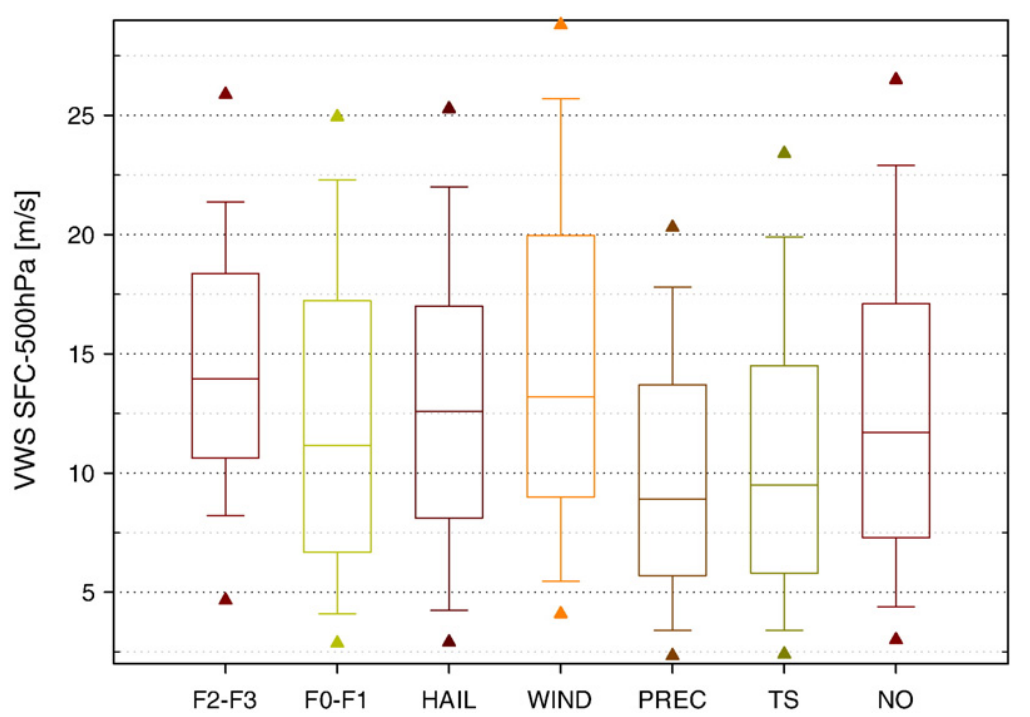

Fig. 10. As in Fig. 4, but for vertical wind shear between lowest model level and $500 \mathrm{hPa}$.

values of $400 \mathrm{~J} / \mathrm{kg}$. The median value was approximately $1000 \mathrm{~J} / \mathrm{kg}$ for HAIL cases (Fig. 8). For hail events, consistent to the US (e.g. Craven et al., 2002), higher CAPE values tend to have more significant severity (e.g. median value at $1100 \mathrm{~J} / \mathrm{kg}$ for hail). Yet in contrast to the US, very high CAPE values are not necessary for significant tornadoes in Europe. Romero et al. (2007) found CAPE values (surface parcel-based) less than $500 \mathrm{~J} / \mathrm{kg}$ for more than half of 85 cases of significant tornadoes in Europe. Fig. 8 reveals median values of CAPE on order of $500 \mathrm{~J} / \mathrm{kg}$. In addition, most reported tornadoes have no accompanied hail reports. In the vicinity of boundary convergence zones, such as sea-breeze fronts (Markowski, 2007; Sills et al., 2004) or topographically modified low-level wind fields (Kaltenböck 2004, 2005; Kaltenböck et al., 2004; Hannesen et al., 1998, 2000) the low-level shear is more important than instability (e.g. Brooks et al., 2007).
The high CAPE values for WIND and PREC highlight the role of convection for these categories. More than $10 \%$ of every individual class have very low values of CAPE and are not representative, e.g. due to frontal passage.

\subsubsection{Showalter index}

The Showalter index (Fig. 9) can be used very well for dichotomous thunderstorm forecasts, applying a threshold value of 3 , which is the value of the 75th percentile for the NO category and approximately the $25 \%$ quantile for all other events. This thunderstorm forecast threshold value is comparable to the one reported for Switzerland (Huntrieser et al., 1997). The median values of SHW are approximately 0 for all severe thunderstorm classes, except for hail with approximately -1 ; hail events occurred in more unstable environment conditions.

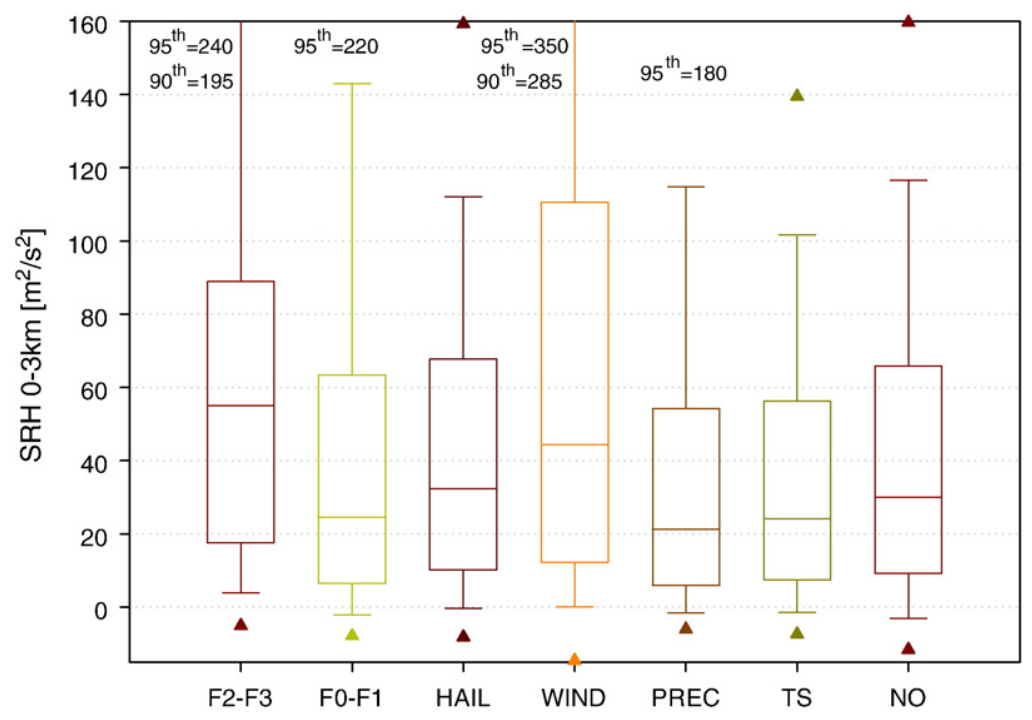

Fig. 11. As in Fig. 4, but for 0-3 km storm-relative helicity. 


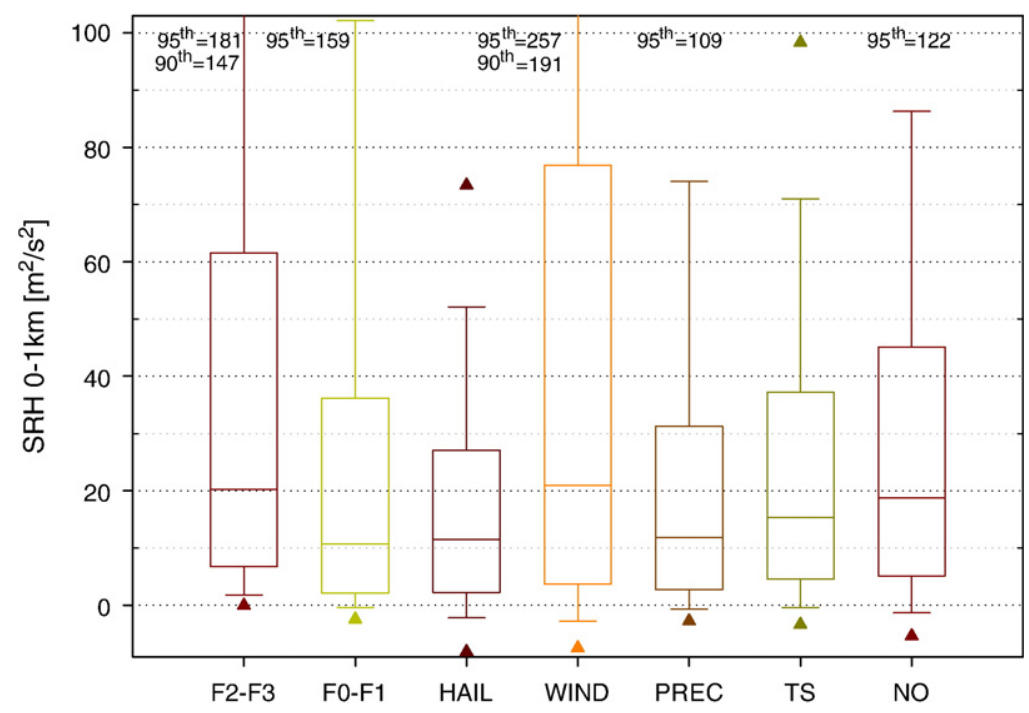

Fig. 12. As in Fig. 4, but for $0-1 \mathrm{~km}$ storm-relative helicity.

\subsection{Kinematic parameters}

\subsubsection{Deep-layer shear}

For this study, the magnitudes of vector difference between the wind at lowest model level and $500 \mathrm{hPa}$ (VWS $\mathrm{SFC}-500 \mathrm{hPa}$ ) were investigated. Results were nearly identical to vertical shear values between 0 and $6 \mathrm{~km}$ (not shown) and distinguish better between different classes than vertical wind shear between 850 and $500 \mathrm{hPa}$.

Strongest vertical wind shear was analysed for F2/F3 and WIND groups, with respective median values of approximately $14 \mathrm{~m} / \mathrm{s}$ and the 75th percentile close to $20 \mathrm{~m} / \mathrm{s}$ (Fig. 10). This parameter discriminated well between ordinary thunderstorms (median: $9.5 \mathrm{~m} / \mathrm{s}, 3 / 4$ of TS cases have values below $14.5 \mathrm{~m} / \mathrm{s}$ ) and severe local events (except for PREC classification) and is comparable to observations from Austria (Kaltenböck, 2005). Most heavy rain cases were caused by slow-movers (low synoptic flow, Fig. 5) and weak vertical deep-layer shear, accompanied by moderate to high CAPE values (median approximately $550 \mathrm{~J} / \mathrm{kg}$, Fig. 8).

\subsubsection{Low-level shear}

In this study, most striking features result from stormrelative helicity (SRH) compared to the magnitudes of vector difference and helicity calculations. SRH has received widespread acceptance within the operational forecasting community as a supercell and tornado forecast parameter (Thompson et al., 2004; Kaltenböck, 2004, 2005). SRH from model surface to $3 \mathrm{~km}$ height is calculated (Fig. 11), which is commonly used as diagnostic forecast parameter (e.g. Kaltenböck, 2004, 2005) and more robust in hilly and mountainous areas in Central Europe than shallow layer wind shear. To point out the key role of low-level shear for producing tornadic supercells, shallow SRH between the lowest model level and $1 \mathrm{~km}$ height and in addition, to the LCL height, were investigated. For SRH calculation, the storm motion was estimated as $75 \%$ of the magnitude of the mean wind of the layer between 0 and $6 \mathrm{~km}$, and applying a deviation of direction of $30^{\circ}$ to the right (e.g. Davis and Johns,
1993 or Romero et al., 2007). The calculation of SRH is very sensitive to the estimated storm motion (e.g. Kaltenböck, 2005). Observations of storm motion demonstrate that movement of storms is not constant in direction and speed. Hence, this parameter should be adapted for short-range forecasting by using actual observations such as surface data and remote sensing data to modify the vertical wind profile and storm motion (Kaltenböck, 2004).

Fig. 11 shows SRH for the $0-3 \mathrm{~km}$ layer. Median values for severe events are weaker than for case studies (e.g. Kaltenböck, 2004) or for analyses of radio-soundings for severe deep convection in Austria (peak value of histogram is $85 \mathrm{~m}^{2} / \mathrm{s}^{2}$, Kaltenböck, 2005), the Netherlands (Groenemeijer, 2005) or in the US (Rasmussen and Blanchard, 1998). In the vicinity of mountain ridges the modification of the low level wind fields, which enhances the low level directional shear, was shown to play an important role in Europe for the initiation and development of severe local storms (Hannesen et al., 1998, 2000; Dotzek, 2001; Kaltenböck, 2004, 2005; Kaltenböck et al., 2004; Dotzek and Friedrich, 2009-this issue). Brooks (2007) confirms this stronger topographic forcing over Europe, obtained from proximity sounding comparison between Europe and the US.

Ordinary thunderstorm, weak tornado, hail and precipitation events occurred in the same range of SRH-0-3 km values (median of approximately $30 \mathrm{~m}^{2} / \mathrm{s}^{2}$ ). Significantly higher values for F2/F3 and WIND groups (median: $50 \mathrm{~m}^{2} / \mathrm{s}^{2}$ ) were analysed. The latter hint indicates a possible relationship between the occurrence of wind events and tornadoes. Two reasons are conceivable: (a) a common mechanism for tornado and downdraft-production in thunderstorms (cf. Giaiotti et al., 2007) or (b) ESWD reports with insufficient evidence for having been tornadic and which were thus reported as damaging wind events only ${ }^{1}$.

\footnotetext{
1 Note that the ESWD data format allows (and explicitly encourages) to mark such wind events as "possibly tornadic".
} 


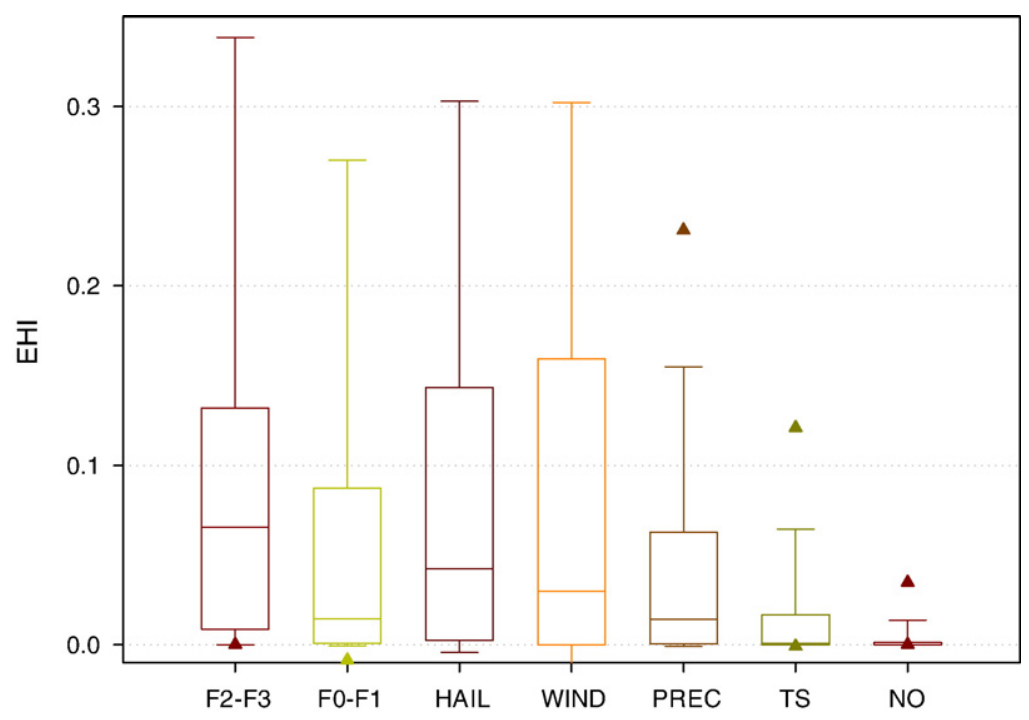

Fig. 13. As in Fig. 4, but for the energy helicity index using SRH 0-1 km.

SRH 0-3 km seems to be a useful discriminating factor for significant and non-significant tornadoes (median value 25 compared to $55 \mathrm{~m}^{2} / \mathrm{s}^{2}$ ). Lower values, but also pronounced differences are found in Fig. 12, where SRH between model surface and $1 \mathrm{~km}$ is presented. SRH $0-1 \mathrm{~km}$ discriminates very well between significant tornadoes and F0/F1 or hail. $75 \%$ of the latter cases show values below $36 \mathrm{~m}^{2} / \mathrm{s}^{2}$. But the highest SRH values still occur for WIND events, their median is similar to the F2-F3 category.

Additionally, the impact of variable effective low-level wind shear layer depth instead of fixed $0-3 \mathrm{~km}$ or $0-1 \mathrm{~km}$ layers for effective SRH calculation was investigated (Thompson et al., 2004). No improvements to distinguish between significant and weak tornadoes could be found (not shown). Unfortunately an overlap between the middle $50 \%$ still remains.

3.4. Combination of instability and vertical wind shear (VWS) parameters

There were no differences in the CAPE and VWS parameters for each individual convection mode. Composite parameters, e.g. CAPE*VWS did not enhance differences in parameter to get better forecast predictors for different severe storm classes. Reasons could be the small sample or an underreporting of F2 and F3 events, the synchronous occurrence of different severe events (e.g. tornado accompanied by hail) and standard values of CAPE and SRH, which

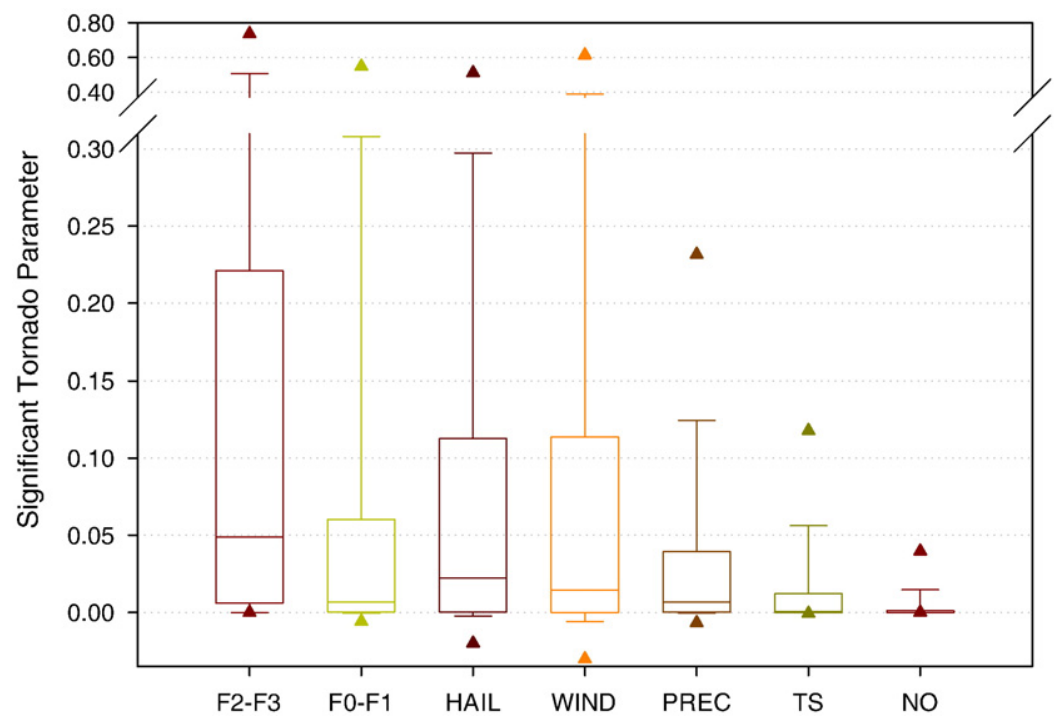

Fig. 14. As in Fig. 4, but for the significant tornado parameter. 
seem to be lower for Europe than in the US. This can lead to incorrect interpretation of the index when used in Europe (Doswell and Schultz, 2006).

Fig. 13 shows the box-and-whiskers plot of Energy Helicity Index (EHI) using low level SRH 0-1 km (Rasmussen 2003):

$\mathrm{EHI}=\mathrm{CAPE}^{*} \mathrm{SRH}{ }_{0-1 \mathrm{~km}} /\left(160000 \mathrm{~J}^{2} / \mathrm{kg}^{2}\right)$.

The median value of F2/F3 category (0.065) differs most from F0/F1 (0.015) and other classes. About 2/3 of cases of the significant tornado category exceeded values of 0.01 , while $2 / 3$ of TS cases were below 0.017 . But, EHI is not the best discriminator between different severe storm events due to the overlapping middle $50 \%$ box. The values are lowercompared to US (Rasmussen, 2003) where the supercell category showed a median value of 0.12 and nearly $2 / 3$ of tornado soundings had values above 0.5 .

The significant tornado parameter (STP) in Fig. 14 was calculated using the same thresholds as Thompson et al. (2003). Modification of the scaling constants to European standard environmental conditions, which favour severe storms was poorer in discriminating between different classes. STP is calculated from:

$\mathrm{STP}=\frac{\text { CAPE }}{1000 \mathrm{Jkg}^{-1}} * \frac{\text { VWS0_6 }}{20 \mathrm{~ms}^{-1}} * \frac{2000-\text { heightLCL }}{1500 \mathrm{~m}}$

The combination of the many parameters to form the STP provided no striking differences to distinguish between significant tornadoes and wind events, but worked sufficiently to separate the F2/F3 category from other groups (threshold value 0.05 ). More than $50 \%$ of significant tornado cases exceeded this value.

\section{Conclusion and future work}

A large dataset from ESWD provided severe storm reports for 2006 and 2007 on a European scale and associated EUCLID lightning data provide well-defined null cases (ordinary or no thunderstorm category). Additionally, ESWD data were used to distinguish between five severe weather categories. Not all data in the database have the highest of the three quality-control levels, and in some regions, severe events may be underreported. Therefore, geographical and reporting biases result and smooth the thresholds for calculated predictors. ECMWF analyses were used to create close pseudo proximity soundings to investigate environmental conditions associated with different types of severe thunderstorms, ordinary thunderstorms and no thunderstorm cases. These offer 1309 locations in Europe associated with 3406 local severe events which have been analysed with the following results.

The numbers of severe weather reports are naturally correlated to population density. Severe events occurred more frequently in summer (May/June to August), with a pronounced diurnal cycle. More CG lightning was likely during days with severe weather, especially with hail, wind and precipitation events from organized and clustered thunderstorm systems. Most severe events were associated with stronger south-westerly flow at $500 \mathrm{hPa}$ (in contrast to westerly and north-westerly flow for non-thunderstorm events), except heavy rain events which indicates the influence of slow movers. South-westerly flow advects warm and moist air, and thunderstorms were more likely when dew points exceeded $10{ }^{\circ} \mathrm{C}$. Severe events were more likely when dew points exceeded $13{ }^{\circ} \mathrm{C}$ (median value of $16.5{ }^{\circ} \mathrm{C}$ for F2/F3 tornadoes (cf. Bissolli et al., 2007). These findings correspond to lower LCL height for tornadoes and precipitation events (median value of $450 \mathrm{~m}$ AGL).

An analysis of thermodynamic and kinematic environmental structures revealed the following:

CAPE can be used to discriminate between thunderstorm and no thunderstorm group (about $250 \mathrm{~J} / \mathrm{kg}$ ) as well as a threshold of the Showalter index of 3. Further, CAPE predicts the probability of severe events when $500 \mathrm{~J} / \mathrm{kg}$ is exceeded;

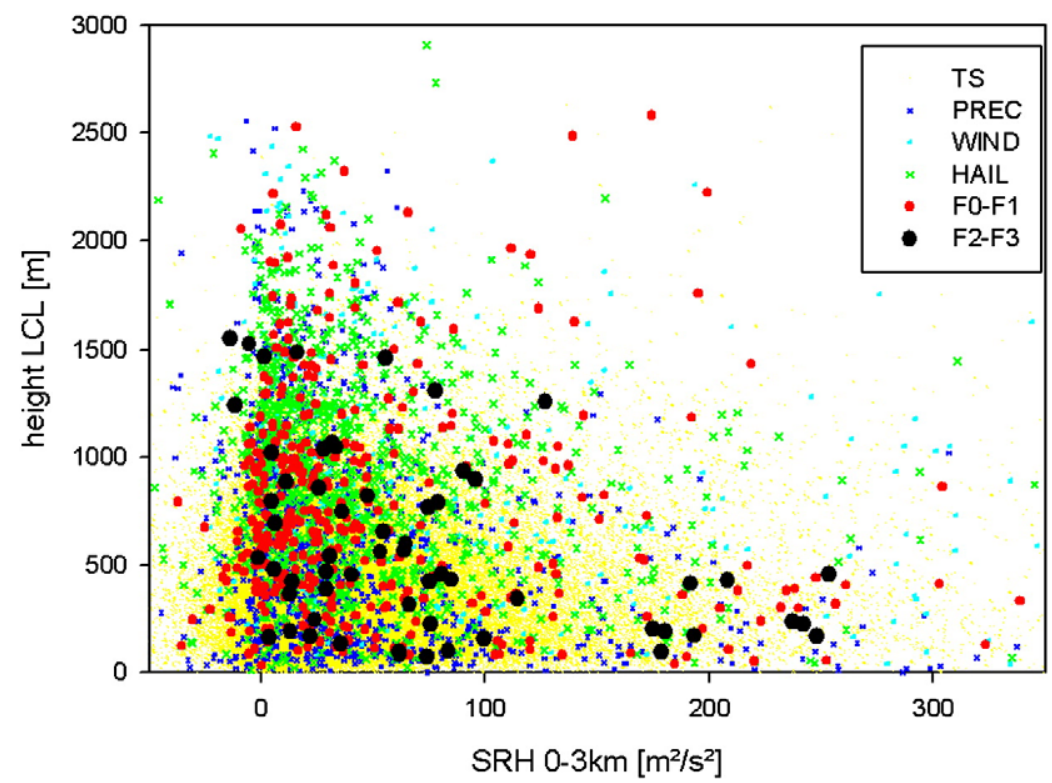

Fig. 15. Scatter plot of storm-relative helicity $(0-3 \mathrm{~km})$ and height of lifting condensation level for different severe and ordinary thunderstorm categories. 


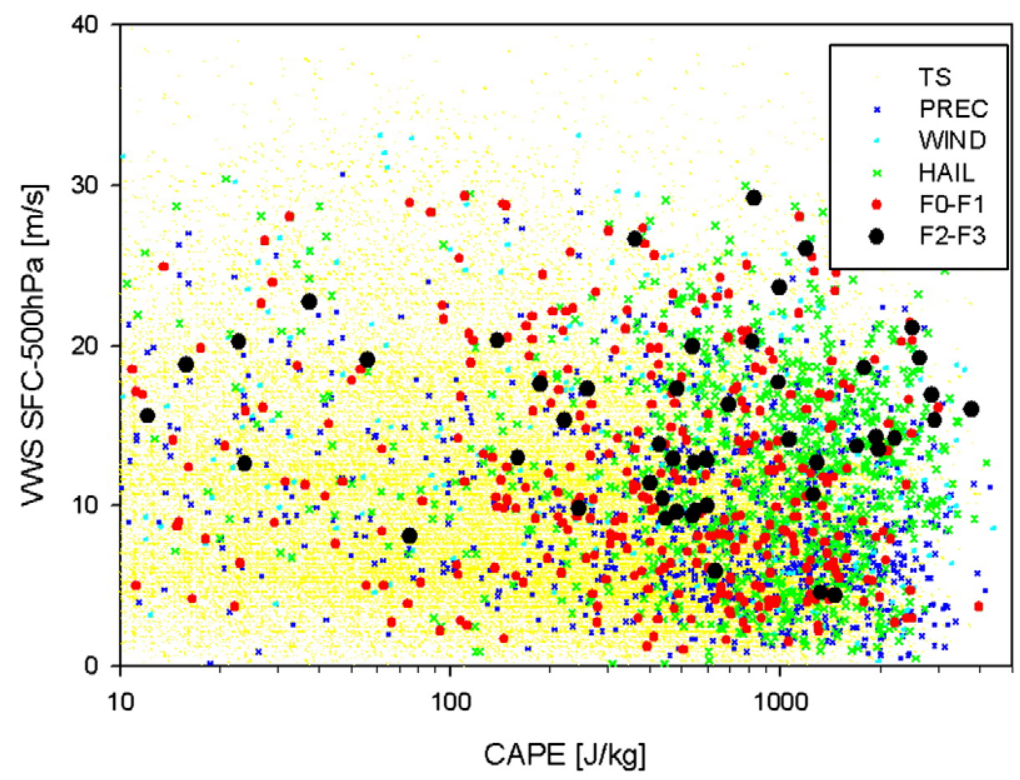

Fig. 16. As in Fig. 15 but with respect to vertical wind shear between lowest model level and $500 \mathrm{hPa}$ and surface-parcel based CAPE. Horizontal axis is in log space.

especially hail cases show highest values. Most tornadoes occurred within moderate CAPE environment.

Highest median value of deep-layer wind shear (from surface to $500 \mathrm{hPa}$ ) was found for F2/F3 and WIND events (approximately $14 \mathrm{~m} / \mathrm{s}$ ). Forecasters should be aware of a severe storm threat when VWS SFC-500 hPa is in excess of $10 \mathrm{~m} / \mathrm{s}$ during unstable conditions. The range of SRH between surface and $3 \mathrm{~km}$ height, which is more robust in mountainous and hilly terrain, ranged from 10 to $110 \mathrm{~m}^{2} / \mathrm{s}^{2}$ and can rather well discriminate between significant tornado/severe wind gusts and other groups (threshold about $50 \mathrm{~m}^{2} \mathrm{~s}^{-2}$ ). The low-level shear (SRH 0-1 km) has lower values, but is an additional discriminator between F2/ F3 or WIND and all other classes. Hail events accompanied by moderate to strong deep-layer shear did not need strong lowlevel shear (median of SRH 0-1 km below 11.5).

At last, composite parameters show no clear skill to distinguish better than single proximity sounding-derived parameters from model data. Most of the parameters are correlated and reveal no clear thresholds due to overlapping ranges. Figs. 15 and 16 illustrate the difficulties to select valuable predictors with severe events embedded in 99,664 cases of ordinary thunderstorms. Severe events were generally found at lager shear and CAPE than ordinary thunderstorms. The likelihood of tornadoes, especially for F2 or higher, increased with lower heights of LCL. The EHI discriminated between F2/F3 and other classes (threshold approximately 0.065). This works better with the use of STP value exceeding 0.05 for the occurrence of significant tornadoes.

The forecast of thunderstorms over entire Europe from model-derived indices works quite well. Even the discrimination between severe and non-severe events delivered acceptable results. Severe storm forecasters need to be aware of the limitations of using indices, summarized by Doswell and Schultz (2006). The challenge for further work is to predict the mode of severe events and the onset time of deep convection. In this study, no parameter and corresponding threshold could be defined as forecast predictor for different severe events, especially between significant tornadoes and wind events. Reasons for this are likely similar physical processes for their occurrence or the mesoscale influences (e.g. orography, sea breeze, ...).

These findings should be further investigated based on a longer time period containing more significant events, as well as by case studies or/and with the aim of high resolution numerical models to figure out the important role of local and mesoscale effects for producing severe thunderstorms. In this context, different geographical regions should be defined, e.g. coastal areas affected by maritime air masses (e.g. Tudurí and Ramis, 1997 for Mediterranean) or mountainous regions and their specific modified wind- and temperature fields.

Other sounding parameters and combinations related to severe events should be further investigated (e.g. DCAPE, create threshold values for European STP, lightning rates, categories based on air masses...). Additionally shorter time intervals of model data are needed and a greater amount than the present 60 significant tornadoes is needed to reduce potential reporting biases and to obtain more robust results from statistical analyses.

\section{Acknowledgements}

The authors are grateful to the ECMWF for providing the high-resolution analyses. Additional thanks go to Georg Mayr (Institute of Meteorology and Geophysics, Innsbruck University) for providing the CAPE source code and for valuable discussions. We would also like to thank three reviewers for their thoughtful and detailed suggestions. ND's contribution to this work was partly funded by the German Ministry for Education and Research (BMBF) under contract 01LS05125 in the project RegioExAKT (Regional Risk of Convective Extreme Weather Events: User-oriented Concepts for Trend Assessment and Adaptation, www regioexakt.de) within the research program klimazwei. 


\section{References}

Bidner, A., 1970. The Air Force Global Weather Central severe weather threat (SWEAT) index- a preliminary report. Air Weather Service Aerospace Science Review, AWS RP 105-2, No. 70-3, pp. 2-5. [Available from Headquarters, AWS, Scott AFB, IL62225].

Bissolli, P., Grieser, J., Dotzek, N., Welsch, M., 2007. Tornadoes in Germany 1950-2003 and their relation to particular weather conditions. Glob. Planet. Change 57, 124-138.

Brooks, H.E., 2007. Proximity sounding for Europe and the United States from reanalysis. Abstract, 4th European Conference on Severe Storms, OSMER ARPA FVG, Trieste, Italy.

Brooks, H.E., Craven, J.P., 2002. A database of proximity soundings for significant severe thunderstorms, 1957-1993. Preprints 21st Conf. on Severe Local Storms, San Antonio, Texas, 12-16 August 2002. Amer. Meteor. Soc., Boston, pp. 639-642.

Brooks, H.E., Dotzek, N., 2008. The spatial distribution of severe convective storms and an analysis of their secular changes. In: Diaz, H.F., Murnane, R. (Eds.), Climate Extremes and Society, 340. Cambridge University Press, Cambridge, pp. 35-53.

Brooks, H.E., Doswell III, C.A., Cooper, J., 1994. On the environments of tornadic and nontornadic mesocyclones. Weather Forecast. 9, 606-618.

Brooks, H.E., Anderson, A.R., Riemann, K., Ebbers, I., Flachs, H., 2007. Climatological aspects of convective parameters from the NCAR/NCEP reanalysis. Atmos Res. 83, 294-305.

Craven, J.P., Brooks, H.E., Hart, J.A., 2002. Baseline climatology of sounding derived parameters associated with deep, moist convection. Preprints 21st Conf. on Severe Local Storms, San Antonio, Texas, 12-16 August 2002. Amer. Meteor. Soc., Boston, pp. 643-646.

Davis, J.M., Johns, R.H., 1993. Some wind and instability parameters associated with strong and violent tornadoes. Part I: Wind shear and helicity. In: Church, C., et al. (Ed.), The Tornado: Its Structure, Dynamics, Prediction and Hazards. Amer. Geophys. Union, Geophys. Monogr., vol. 79, pp. 573-582.

Doswell III, C.A., 1994a. Flash flood-producing convective storms: current understanding and research. In: Corominas, J., Georgakakos, K.P. (Eds.), Report of the Proceedings of the U.S.-Spain Workshop on Natural Hazards (Barcelona, Spain, 8 -11 June 1993), pp. 97-107. [Available from the Iowa Institute of Hydraulic Research, University of Iowa, Iowa City, Iowa 52242].

Doswell III, C.A., 1994b. Extreme convective windstorms: current understanding and research. In: Corominas, J., Georgakakos, K.P. (Eds.), Report of the Proceedings of the U.S.-Spain Workshop on Natural Hazards (Barcelona, Spain, 8- 11 June 1993), pp. 44-55. [Available from the Iowa Institute of Hydraulic Research, University of Iowa, Iowa City, Iowa 52242].

Doswell III, C.A., Schultz, D.M., 2006. On the use of indices and parameters in forecasting severe storms. Electronic J. Severe Storms Meteor. 1, 1-14.

Doswell III, C.A., Brooks, H.E., Maddox, R.A., 1996. Flash flood forecasting: an ingredients-based methodology. Weather Forecast. 11, 560-580.

Dotzek, N., 2001. Tornadoes in Germany. Atmos. Res. 56, 233-252.

Dotzek, N., 2003. An updated estimate of tornado occurrence in Europe. Atmos. Res. 67-68, 153-161.

Dotzek, N., Friedrich, K., 2009. Downburst-producing thunderstorms in southern Germany: radar analysis and predictability. Atmos. Res. 93, 457-473 (this issue).

Dotzek, N., Höller, H., Théry, C., Fehr, T., 2001. Lightning evolution related to radar-derived microphysics in the 21 July 1998 EULINOX supercell storm. Atmos. Res. 56, 335-354.

Dotzek, N., Lang, P., Hagen, M., Fehr, T., Hellmiss, W., 2007. Doppler radar observation, CG lightning activity, and aerial survey of a multiple downburst in southern Germany on 23 March 2001. Atmos Res. 83, 519-533.

Dotzek, N., Groenemeijer, P., Feuerstein, B., Holzer, A.M., 2009. Overview of ESSL's severe convective storms research using the European Severe Weather Database ESWD. Atmos. Res. 93, 575-586 (this issue).

ESSL, 2006. ESWD Version 1.40 data format description. ESSL Tech. Rep. 2006-01, July 2006. . 26 pp. [Available online: http://essl.org/reports/ tec/ESSL-tech-rep-2006-01.pdf].

EUCLID, 2007: [Available online: http://www.euclid.org].

Galway, J.G., 1956. The lifted index as a predictor of latent instability. Bull. Am. Meteorol. Soc. 37, 528-529.

Gayà, M., Homar, V., Romero, R., Ramis, C., 2001. Tornados and waterspouts in the Balearic Islands: phenomena and environment characterization. Atmos. Res. 56, 253-267.

Geerts, B., 2001. Estimating downburst-related maximum surface wind speeds by means of proximity soundings in New South Wales, Australia. Weather Forecast. 16, 261-269.

Giaiotti, D.B., Steinacker, R., Stel, F., 2007. Atmospheric convection: research and operational forecasting aspects. CISM Courses and Lectures no. 475. Springer Verlag, Wien. 227 pp.
Groenemeijer, P.H., van Delden, A., 2007. Sounding-derived parameters associated with large hail and tornadoes in the Netherlands. Atmos. Res. 83, 473-487.

Hannesen, R., Dotzek, N., Gysi, H., Beheng, K.D., 1998. Case study of a tornado in the Upper Rhine valley. Meteorol. Z. 7, 163-170 [Available at essl.org/ people/dotzek/].

Hannesen, R., Dotzek, N., Handwerker, J., 2000. Radar analysis of a tornado over hilly terrain on 23 July 1996. Phys. Chem. Earth B25, 1079-1084 [Available at essl.org/people/dotzek/].

Holzer, A.M., 2001. Tornado climatology of Austria. Atmos. Res. 56, 375-396.

Hohl, R., Schiesser, H.-H., 2001. Cloud-to-ground lightning activity in relation to the radar-derived hail kinetic energy in Switzerland. Atmos. Res. 56, 375-396.

Huntrieser, H., Schiesser, H.H., Schmid, W., Waldvogel, A., 1997. Comparison of traditional and newly developed thunderstorm indices for Switzerland. Weather Forecast. 12, 108-125.

Johns, R.H., Doswell III, C.A., 1992. Severe local storms forecasting. Weather Forecast. 8, 559-569.

Kaltenböck, R., 2000a. Der Einfluß der vertikalen Windscherung auf die Bildung von Gewittern. CD-Rom, Austrocontrol, Vienna, Austria.

Kaltenböck, R., 2000b. Nowcasting of mesoscale phenomena in Austria: thunderstom initiation-convergence lines north of the Alps, dry and wet cases. International Training Workshop on Nowcasting in Sydney, WMO World Weather Research Program- Forecasting Demonstration Project Sydney 2000, CD-Rom. Bureau of Meteorology, Sydney, Australia.

Kaltenböck, R., 2004. The outbreak of severe storms along convergence lines northeast of the Alps. Case study of the 3 August 2001 mesoscale convective system with a pronounced bow echo. Atmos. Res. 70, 55-75.

Kaltenböck, R. 2005. Nowcasting of thunderstorms using mesoscale modified low level wind in Austria. WMO's Word Weather Research Programme Symposium on Nowcasting and Very Short Range Forecasting, CD-Rom, Meteo-France, Toulouse, France. [Available at http://www. meteo.fr/cic/wsn05/DVD/posters/Kaltenbock-2.16/Poster-Kaltenbock2.16.jpg].

Kaltenböck, R., Kerschbaum, M., Pistotnik, G., Pöttschacher, W., Ratheiser, M., Svabik, O., 2004. Orographic influences on a tornadic supercell formation over Vienna-Austria. Abstract, 3rd European Conference on Severe Storms, Leon, Spain.

Markowski, P., 2007. Tornadoes and tornadogenesis, In: Giaiotti, D.B. Steinacker, R., Stel, F. (Eds.), Atmospheric Convection: Research and Operational Forecasting Aspects. CISM Courses and Lectures no. 475. Springer Verlag, Wien, pp. 45-55.

Monteverdi, J.P., Doswell III, C.A., Lipari, G.S., 2003. Shear parameter thresholds for forecasting tornadic thunderstorms in northern and central California. Weather Forecast. 18, 357-370.

Mills, G.A., Colquhoun, J.R., 1998. Objective prediction of severe thunderstorm environments: preliminary results linking a decision tree with operational regional NWP model. Weather Forecast. 13, 1078-1092.

Rasmussen, E.N., 2003. Refined supercell and tornado forecast parameters. Weather Forecast. 18, 530-535.

Rasmussen, E.N., Blanchard, D.O., 1998. A baseline climatology of soundingderived supercell and tornado forecast parameters. Weather Forecast. 13, $1148-1164$.

Reap, R.M., 1986. Evaluation of cloud-to-ground lightning data from the Western United States for the 1983-1984 summer seasons. J. Clim. Appl. Meteorol. 25, 785-799.

Romero, R., Guijarro, J.A., Ramis, C., Alonso, S., 1998. A 30 year (1964-1993) daily rainfall data base for the Spanish Mediterranean regions: first exploratory study. Int. J. Climatol. 18, 541-560.

Romero, R., Gaya, M., Doswell III, C.A., 2007. European climatology of severe convective storm environmental parameters: a test for significant tornado events. Atmos. Res. 83, 389-404.

Schmid, W., Schiesser, H.-H., Furger, M., Jenni, M., 2000. The origin of severe winds in a tornadic bow-echo storm over northern Switzerland. Mon. Weather Rev. 128, 192-207.

Showalter, A.K., 1953. A stability index for thunderstorm forecasting. Bull. Am. Meteorol. Soc. 250-252.

Sills, D.M.L., Wilson, J.W., Joe, P.I., Burgess, D.W., Webb, R.M., Fox, N.I., 2004. The 3 November tornadic event during Sydney 2000: storm evolution and the role of low-level boundaries. Weather Forecast. 19, 22-42.

Soula, S., Seity, Y., Feral, L., Sauvageot, H., 2004. Cloud-to-ground lightning activity in hail-bearing storms. J. Geophys. Res. 109, D02101. doi:10.1029/ 2003JD003669.

Steinacker, R., 1977. Möglichkeiten von Gewitterprognosen im Gebirge. Wetter Leben 29, 150-156.

Teittinen, J.T., LaDue, J.G., Hohti, H., Brown, R.A., 2006. Radar characteristics of a tornadic low topped mini-supercell in Finland. Proceedings of 4th European Conference on Radar in Meteorology and Hydrology, Barcelona, Spain, pp. 484-487. 
Thompson, R.L., 1998. Eta model relative-storm winds associated with tornadic and nontornadic supercells. Weather Forecast. 13, 125-137.

Thompson, R.L., Edward, R., Hart, J.A., Elmore, K.L., Markowski, P., 2003. Close proximity soundings within supercell environments obtained from the rapid update cycle. Weather Forecast. 18, 1243-1261.

Thompson, R.L., Edwards, R., Mead, C., 2004. Effective Storm-Relative Helicity in Supercell Thunderstorm Environments. Preprints, 22nd Conference on
Severe Local Storms, Hyannis, MA, [Available online: http://www.spc. noaa.gov/publications/thompson/effshear.pdf].

Tudurí, E., Ramis, C., 1997. The environments of significant convective events in the western Mediterranean. Weather Forecast. 12, 294-306.

Williams, E.R., 2001. The electrification of severe storms. In: DoswellIII III, C.A. (Ed.), Severe Convective Storms. Amer. Meteor. Soc., Boston, Meteor. Monogr., vol. 28 (50), pp. 527-561. 